\title{
Assessing Students Critical Literacy Capacity: Feasible or Impractical?
}

\author{
Failasofah \\ Universitas Jambi, Jambi, Indonesia \\ failasofah.unja@gmail.com
}

\begin{abstract}
Critical literacy skill, particularly proficiency in reading and writing, could be essential for students to be really prepared for college, work, and citizenship. Students are not only able to read text and write words but also empowered to consciously analyze, assess, categorize, induce, deduce, synthesize, and abstract when faced with the information in any form of message with multiple viewpoints. Hence, educators in the field of teaching English as a foreign language (TEFL) should collaborate with their students to understand how texts in different languages and culture work within school context which is also grounded in learners' lives and their social context. However, examination-oriented education system, according to Koo (2012), leads to an uncritical thinking culture in schools. Most of them are only trained to have good result on their examination using some strategies in answering questions. Therefore, this pilot study is aimed to investigate the attitude of some high school teachers concerning the feasibility of assessing students' critical literacy capacity. Designed with qualitative method, the data was collected from in-depth interviews with some respondents to know their view and behaviour on the issue. The data were analysed using within-case and cross-case displays and analysis.
\end{abstract}

Keywords: Critical Literacy, TEFL, assessment

\section{INTRODUCTION}

Literacy is learned by most of human from the first time we begin to communicate to others by acquiring the particular way of communication in our family and community. That skill becomes the basic competence to help them to understand all kinds of sign and symbol in our life. In this century, most of people agree with the view that literacy is significant aspect for successfulness as an individual and as a member of society (Weigle, 2014). People are demanded to understand and comprehend every kind of information which critical thinking as the main capacity is needed (Emilia, 2005).

This capacity, critical thinking in literacy, is required more as a child enters his formal education such as at school. He gets some inputs and has to respond to them using his language as a means of communication, especially in the school context. He has to deal with some different type of written and spoken discourses of his friends, teachers, administrators, books, materials, learning media, and so on. This competence is also indicated in Indonesian English curriculum for high school students, KTSP and Kurikulum 2013. Some competences, correspondingly, should be acquired by them such as the ability to respond the meaning of a text functionally in context, the ability to comprehend the social function of discourses, and the ability to interact with others in their society in a proper behaviour.

Students' achievement of those competences should be assessed as the reference for teachers that they have delivered and conveyed the proficiencies effectively, and it is likewise to improve their teaching or to develop new lesson plan. Assessing students' critical literacy skill should be in a relevant method since it should evaluate students understanding how written or spoken texts work, what texts intend to do to the world, and how social relations can be critiqued and reconstructed. Some related studies on students' critical thinking ability in comprehending and responding to texts showed that most of undergraduate and some of graduate students are indeed lacking in that skill (Koo, 2012). The purpose of this qualitative inquiry was to explore and describe the attitude of some high school teachers concerning the feasibility of assessing students' critical literacy capacity. One major question in this study: What are high school teachers' perspectives of the necessity and the possibility of assessing students' critical literacy capacity?

\section{LITERATURE REVIEW}

There are three concerns, since 1960s, which have dominated language testing: how to test, what to test, and who are the testers? Those concerns, which was guided this study, are also needed in assessing students. Some considerations of how the assessment is processed by the teachers will impact the reliability of it. Teachers should think about the method of the assessment, the character and level of the students, and the learning materials that have been given to students. Additionally, they should review the method of analysis. Productive and receptive skills need different analysis whether the items are quantitative or qualitative.

What to assess indicates the teachers' choice of language skill should be tested and evaluated. They are all the information needed by teachers such as students' abilities, characteristics, skills, understanding, and knowledge developed. From the assessment, teacher will obtain some feedback information on how effective his or her teaching and it could be used as a standard for the next curriculum development and improvement (Frey, 2014, Rhodes \& Shanklin, 1993). Since literacy not only requires students' ability in reading and writing text but also requires their competence in interpreting and making meaning of the text based on some viewpoints in context, "Assessing children's 
literate learning requires attending not only to what they know and do also at least as much to the context in which they know and do" (Johnson \& Costello in Antonacci \& O'Callaghan, 2012).

The last concern, who does the assessment, leads to ethic and validity of the assessment and the assessor (Davies, 2014). Teachers' professionalism is important. They have to take into account the effect of their test and evaluation, moreover, they should consider whether it is morally right to develop or use a particular test. Validity, which accountability is also embedded, shows the quality of the process as a judgement on all aspects of the test.

The assessment that is taken by teachers shows them the character and proficiency of their class and they give them clue of what is important in their teaching. Thus, it can also misrepresent teaching objectives, if the students are signed to be more focus on performing well on their tests (Shepard, 2013). Therefore, any kind of summative tests should be profoundly grounded in subject-matter content and processes.

In summary, the consideration of how to assess, what to assess, and who does the assessment has guided this study to know teachers' attitudes concerning the process of assessing students' critical literacy capacity.

\section{METHOD}

The purpose of this qualitative inquiry was to explore and describe the attitude of some "high school teachers concerning the process of critical literacy assessment in their schools. Qualitative method was chosen because the main purpose of the study is to retrieve descriptive profiles and information from participants and the qualitative method is suitable for this. The main resource for data collection is through interviews. According to Merriam (1998), 'through examining a previously understudied issue, qualitative researchers have a variety of opportunities for doing research on relevant issues and aspects and may contribute to provide a framework or foundation for other inquiries." To achieve the purpose of this study, I decided to use a case study design as my appropriate research strategy.

The sites for this study were five high schools inside and outside Jambi city, Indonesia. These five schools were varied in terms of socioeconomic students, achievements, and facilities. For sampling, in this study, I used a purposeful sampling with a convenience case strategy. Cresswell (2007) wrote, "Convenience cases, which represent sites or individuals from which researcher can access and easily collect data" (p. 126). I used this strategy in choosing the research sites and participants because we had access to do research and collect data at the sites as Johnson and Christensen (2008), Cresswell (1998, 2007), Bogdan \& Biklen (1998), and Merriam (1999) said that getting access is very essential in doing and collecting qualitative data.

All interviews were recorded with the consent of the participants and transcribed. Interview data obtained were organized and analyzed for regularities, patterns, and emerging topics. To establish the trustworthiness or to verify the accuracy of data and interpretations (Creswell, 1998,
2007), the data, interpretations, and conclusions were shared with the participants to get their feedback on the accuracy and credibility of the data, interpretations, and conclusions.

\section{FINDING AND DISCUSSION}

High school teachers from this study share almost similar negative attitudes concerning the feasibility of assessing students' critical capability in literacy. They think that there are some problems that make them not able to explore and assess students' ability in literacy critically. They have to face with the limited time allotment, lack of schools supports in generating students' critical capacity, and their limited understanding on the issue itself that leads to their limited potential to develop a proper form of assessment.

4.1 Teacher critical literacy awareness

Critical literacy awareness is the process of thinking critically to analyze and critique the information of social, cultural, and political power that one received. That awareness is needed when people interact with texts as medium of our communication. We have to interpret and make proper meaning on them in order to be successful in our exchange. As the person in charge to students' assessment, teachers' should be more aware of how to be critical and how to promote it to students. Regrettable, some researches proved that not only teachers who do not aware of critical literacy when they read or write but some teachers were also did not aware of it. Koo (2012) stated that most Malaysian students, even at the postgraduate level as lecturer, tend to be uncritical to socialization processes in the educational and sociocultural environment.

Absence of the awareness also revealed at some of my participants responses.

(Teacher A)

"Critical literacy means to be good in reading."

"Have good understanding of the text and can answer the entire questions." (Teacher D)

Knowing or realizing that critical literacy aims to encourage students to question what is going on around them, it becomes important as one of national English curriculum objectives is to generate students who understand functional language in context. Students are now not only need to understand what they are reading, but also have to look deeper to find out the author's message and to find out the reason they wrote in particular topic and style. Moreover, with so many kinds of information these days, students literacy competence involves consideration of both the multiplicity of linguistics and cultural variations faced by students in a globalized world and the variety of new text types they encounter beyond the printed world (Weigle, 2014). As the essential basic knowledge, literacy is not as simple as knowing how to read and answer some questions related to it. Responding to that issue, one participant said:

"We have to effectively use our time for English subject. So, using the text available in the textbook, I explain some other issues like diversity, emotion, and culture." (Teacher B) 
"I think discussing about culture and emotion are useful to be explored because there will be a lot of information to be gained from that topic." (Teacher D)

These two participants have more awareness of the necessity of generating students' competence in viewing some critical elements that surround a text.

\subsection{English Assessment}

Teachers' responsibility to assess their students' literacy skill covers some development areas such as the varied symbolic of ideas presented and different ways of thinking, reading, writing, and speaking in different disciplines. It needs students' capacity for thinking critically with the involvement of students ability to look beyond the literal meaning to observe what is present and what is missing (Huffman, 2013). Thus, Warriner (2007) mentioned that when students are learning how to decode the meaning of words and questions on multiple-choice tests, how to choose correctly from among the available options, and how to fill in the circles on the answer key, they are not engaged in meaningful reading and writing experiences, authentic faceto-face communication, or general problem-solving activities that would help them achieve some of their most important goals in global literacy.

"I think to explore their critical thinking capacity, teacher needs more time. Ideally $K-13$ has good objective for students that they will have competences to produce English written and spoken for global communication. But, at the end, UN demands them to answer multiple choice questions which only ask the surface knowledge, not in depth." (Teacher B)

This participant realizes that students need to be encouraged to express their ideas and perspectives about the text they are reading or writing.

"Yes. I ask them to identify different context, culture, and value. They have to show their knowledge in the global mindset." (Teacher B)

Thus, other participant who has critical literacy awareness feels that the required assessment seems to be unfeasible to do.

"Yes. But it is still not interpreted into effective instructions. Teachers are oriented to answering questions for standardized exam." (Teacher E)

\section{CONCLUSION}

Negative perspectives that were shared by some teachers concerning assessing their students' capacity in understanding texts in literacy and interpreting them using their different viewpoints, experiences, beliefs, cultures, and some other influenced aspects is caused by some problems they faced at their schools. They have to deal with the form of their school's assessment that they do not able to employ authentic assessment needed. Some of them even have a very limited awareness of the significant of critical literacy skills to be transferred to students.

\section{REFERENCES}

Antonacci, P. A. \& O’Callaghan, C. M. 2012. Promoting Literacy Development. California: SAGE Publications, Inc.

Bogdan, R. C., \& Biklen, S. K. (1998 ). Qualitative research for education: An introduction to theories and methods (3rd ed.). Boston: Allyn and Bacon.

Creswell, J. W. (1998). Qualitative inquiry and research design: Choosing among five traditions. Thousand Oaks, CA: Sage Publications, Inc.

Creswell, J. W. (2007). Qualitative Inquiry and Research Design: Choosing among Five Traditions. 2nd ed. Thousand Oaks, CA: Sage Publications.

Davies, A. 2014. Fifty Years of Language Assessment. The Companion to Language Assessment, $1^{\text {st }} \mathrm{Ed}$. Chichester: John Wiley \& Sons, Inc.

Frey, B. B., 2014. Modern Classroom Assessment. California: SAGE Publication, Inc.

Huffman, J. 2013. Critical Literacy, an Exploration: The deeper you go, the more you understand. Retrieved on September 20, 2016. https://prezi.com/obs1kmygwbo/critical-literacy-presentation/

Merriam, S. B. (1998). Qualitative research and case study applications in education. San Francisco, CA: Jossey-Bass.

Rhodes, L., \& Shanklin. 1993. Windows into Literacy; Assessing Learners K-8. Pothmouth, NH: Heinemann.

Shepard, Lorrie A. 2013. Research on Classroom Assessment. California: SAGE Publication, Inc.

Warriner, D. S., 2007. "It's Just the Nature of the Beast", Reimagining the Literacies of Schooling in adults ESL Education. Retrieved on September 25, 2016. www.academia.edu.

Weigle, S. C. 2014. Assessing Literacy. The Companion to Language Assessment, $1^{\text {st }}$ Ed. Chichester: John Wiley \& Sons, Inc. 